\title{
THE STRUCTURE AND GUIDELINES OF PRE- VOCATIONAL EDUCATION AND ASSISTANCE FOR PUPILS WITH MILD INTELLECTUAL DISABILITIES
}

\author{
Aiste Valaikiene \\ Siauliai University, Lithuania \\ Irena Kaffemaniene \\ Siauliai University, Lithuania \\ Ingrida Baranauskiene \\ Klaipèda University, Lithuania
}

\begin{abstract}
The research aims to disclose the structure and guidelines of pre-vocational education and assistance for pupils with mild intellectual disabilities. In order to achieve the research aim, the qualitative research was chosen. It was conducted using modified elements of Delphi group discussion method. The study participants were highly qualified specialists (13 experts) with 5 to 25 years' experience of educating pupils with special educational needs or providing educational assistance to them. The authors of the research systematized specialists' approaches towards pre-vocational education of pupils with mild intellectual disabilities, discussed possibilities of improving early preparation of these pupils for the world of labour.
\end{abstract}

Keywords: pre-vocational education, pupils with mild intellectual disabilities.

\section{Introduction}

Significance of the problem. Today's labour market poses particular adaptation difficulties for disabled people. Only a small share of people with disabilities participate in work activities; more often these are people with mild disabilities. People with intellectual disabilities find it especially difficult to find employment and stay in the workplace. The number of available jobs for young people with intellectual disabilities is very low. They are more often dismissed from work compared with others and belong to the only group of the disabled that does not receive wages higher than the minimum (Colella 1996). Persons with mild intellectual disabilities belong to a particularly high-risk group; even acquisition of vocational preparation does not remove a risk of social exclusion, long-term unemployment and falling below the poverty line. People with disabilities are the poorest, the least educated and the least employed part of people (King 1993). As researches conducted by R.M. Baer, A.W. Daviso, R.W. Flexer, R.M. Queen \& R.S. Meindl (2011) demonstrate, career and technical education study programs did not reach significance as predictors of 
post-school employment of students with intellectual disabilities. These findings point to the need for more holistic career education and work study models for students with intellectual disabilities (Baer et al. 2011).

Although in 2014 The Career Guidance Program ${ }^{1}$ was approved in Lithuania, this program is an insufficient precondition for successful professional integration of persons with mild intellectual disabilities. People with the mild intellectual disabilities often experience difficulties of social adjustment and cognitive skills in work and life situations; as a result, failures may influence their self-esteem and enhance lack of confidence in one's own abilities (Baranauskiené, Radzevičienè \& Valaikienè 2012).

Career guidance and preparation for professional integration of pupils with mild intellectual disabilities is a complex problem requiring complex decisions at the level of the state, employers and school. Solution of this problem at the school level first of all necessitates teachers' special preparation and particularly their ability to individualise the content and teaching methods of career guidance. Besides, pupils with MID need assistance not only acquiring a profession but also finding employment and working. It is likely that theoretical and practical justification of pre-vocational education of pupils with MID could create preconditions for more successful integration of those persons into the labour market. However, there are few studies in Lithuania disclosing the specificity of pre-vocational education of pupils with MID in a reasoned way.

The aim of the research presented in this article is to disclose the structure and guidelines of pre-vocational education and assistance for pupils with mild intellectual disabilities.

\section{Relevant Issues of Professional Integration of Persons with Mild Intellectual Disabilities}

Participation of persons with MID in the labour market is complicated in all stages of professional integration (employment, adaptation at the workplace, the ability to adapt to changing labour market requirements). Many researches focus on the lack of social skills of persons with intellectual disabilities (Baranauskienė \& Ruškus 2004; Hallahan \& Kauffman 2003; Kaffemaniene \& Jurevičienè 2012; Rivera \& Pellitteri 2007; etc.). As noted by Rivera \& Pellitteri (2007), reasons of failures at work of persons with MID are most often their own socially maladaptive behaviour, lack of social skills and intrinsic motivation to work. They are characterised by unrealistic assessment of their possibilities, inadequate reaction to criticism (Baranauskienè \& Ruškus 2004);

\footnotetext{
${ }^{1}$ The Career Guidance Program (2014). Register of legal acts, 2014-04-29, No. 2014-04888
} 
they encounter difficulties in social interaction with co-workers and employers (Hallahan \& Kauffman 2003). Employers doubt that people with disabilities can work effectively (King 1993); they expect knowledge, skills and intrinsic motivation from their employees, however, vocational guidance at schools does not meet these expectations (Kuijpers, Meijers \& Gundy 2011). It was found that professional integration of young people with MID is hindered by insufficient literacy, mathematical skills; often their choice of the profession is determined not by knowledge of the profession but by coincidence or influence of other persons (Baranauskienè \& Ruškus 2004). According to Rivera \& Pellitteri (2007), it is necessary to help pupils with MID to construct realistic goals so that they can have possibilities to entrench in the labour market.

The review of scientific researches shows that in many countries persons with intellectual disabilities face similar professional integration problems and this suggests that the problem of employability of these persons requires complex solutions. Pre-vocational education could be one of many ways of solving the professional integration problem. However, so far pre-vocational education of pupils with MID has been hardly analyzed systematically; there is no scientifically grounded curriculum of pre-vocational education of pupils with MID, strategies and structure of assistance provision to the pupil.

The scientific problem of this research is concretized by the problem question: What should be the structural elements of pre-vocational education and assistance for pupils with mild intellectual disorders?

Research methodology and methods. In order to achieve the aim of the research, the qualitative research was chosen. The study was conducted using elements of Delphi group discussion method described by Hsu \& Sandford (2007), Linstone \& Turoff (2002), Sackman (1974) and other authors. The Delphi method was chosen "as a method for structuring a group communication process so that the process is effective in allowing a group of individuals, as a whole, to deal with a complex problem" (Linstone \& Turoff 2002: 3). The essence of the method is by eliminating conformism possibilities, to get as many and as various opinions and statements from experts participating in the group as possible. Imparting the opinion, feedback is emphasized while the conversation is directed not only to the identification of the problem but also to its solution, concrete recommendations, proposals or ideas. The focus of group discussion was on getting experts' practical experience about possibilities of pre-vocational education of pupils with MID. During the research, the open-ended questions were given; Delfi group participants (experts) expressed their views on prevocational education of pupils with MID: goals, forms, methods of education, activity areas, influence of traditions on successful pre-vocational education of pupils with MID, etc. 
Aiste Valaikiene, Irena Kaffemaniene, Ingrida Baranauskiene. The Structure and Guidelines of Pre-Vocational Education and Assistance for Pupils with Mild Intellectual Disabilities

Data analysis methods. Delphi research data were processed combining qualitative and quantitative methodology of the social research (Linstone \& Turoff 2002; Hsu \& Sandford 2007, etc.). Results of Delphi group research were analyzed using qualitative method of content analysis; sub-categories that were given for experts' evaluation were distinguished and ratings of experts' opinions were identified. The spectrum of received opinions reflecting experts' professional experience was systematised and grouped according to similar meanings. Experts' assistance was used to conduct control of distinguishing meaningful units of the content of nomination. Seeking to better understand the spread of experts' opinions, the means and standard deviations of subcategories of research data were calculated.

The research sample. The study was attended by highly qualified specialists with higher education with 5 to 25 years' experience educating pupils with special educational needs or providing educational assistance to them. Study participants were 13 experts ( 2 men and 11 women): 4 special education teachers, 3 social workers, 2 psychologists, 4 vocational education teachers working in general education and vocational schools.

Ethical considerations. The participants were informed about the research aims, methods, confidentiality of their personalities, their free choice to participate in the study and the use of the results before starting the research.

\section{Results}

Content analysis of Delphi discussions highlighted experts' opinion about: 1) pre-vocational education strategies of pupils with mild intellectual disabilities, and 2) trends of these pupils' pre-vocational curriculum.

In the opinion of research participants, key pre-vocational education strategies are: socio-educational assistance to the pupil; school-family cooperation; parent information and counselling.

Socio-educational assistance to the pupil. According to experts, pupils with MID need team assistance of all education assistance specialists (M=4,8; $\mathrm{SD}=0,45)$. Perhaps the most important aims of socio-educational assistance to the pupil, as experts say, should be preparation of the individual plan for the transition from school to professional activities $(\mathrm{M}=4,4 ; \mathrm{SD}=0,89)$; assistance finding appropriate problem solution ways $(\mathrm{M}=4,2 ; \mathrm{SD}=0,83)$, etc. Experts' findings are confirmed by conclusions of other researches. Wagner, Davis (2006) distinguish effective school assistance to the pupil as one of the principles of pre-vocational education (introduction of mentoring programs at schools, provision of support for pupils with SEN, provision of services, etc.).

School-family cooperation. Parents of the pupil with MID should participate in his / her pre-vocational education process. Delfi group experts 
almost unanimously emphasised family involvement not only in the child's prevocational education at school but also in inter-institutional cooperation (parental involvement in cooperation at the inter-institutional and school community level, $\mathrm{M}=4,8 ; \mathrm{SD}=0,45$; close relations between the school, family and vocational guidance services, $\mathrm{M}=4,6 ; \mathrm{SD}=0,55 ;$ organisation of meetings with education assistance professionals, the career counsellor, pre-vocational education coordinator during parents' meetings, $\mathrm{M}=4,4 ; \mathrm{SD}=0,49$ ). Research participants stated that parents should take part both assessing the child's possibilities choosing the profession $(\mathrm{M}=4,2 ; \mathrm{SD}=0,83)$ and in other school activities.

Parent information and counselling. The school should provide parents with educational services related to their child's professional integration prospects $(\mathrm{M}=4,6 ; \mathrm{SD}=0,55)$ : inform about the news and changes in the labour market; about educational institutions in which their children can acquire a profession; about requirements for specific professions. It is necessary to counsel parents so that they can realistically evaluate their child's possibilities $(\mathrm{M}=4,4, \mathrm{SD}=0,54)$ and correctly advise the child choosing the profession and vocational school (parents' purposeful guidance, $\mathrm{M}=4,4 ; \mathrm{SD}=0,54$ ).

Delphi survey results highlighted relevance of cooperation between the learner with MID, his / her family, schools and other social institutions as a precondition for successful pre-vocational education. According to experts, factors, enhancing cooperation between the learner, his/her family and the school are socio-educational assistance to the pupil with MID; parent information and counselling services on issues related to the choice of the profession; purposeful involvement of the family in inter-institutional cooperation, etc.

Trends of pupils' pre-vocational education. Content analysis of discussions disclosed key trends of pre-vocational education of pupils with MID: 1) vocational guidance, 2) vocational counselling, 3) preparation of the world of work; 4) career planning.

Vocational guidance. Experts first of all relate pre-vocational education to vocational informing; knowledge of inclinations and abilities of the pupil with MID; assistance choosing the profession; drawing up the life plan, guidance to study at concrete vocational schools. The school must both provide the pupil with knowledge about professions $(\mathrm{M}=4,8 ; \mathrm{SD}=0,45)$ and inform about personality traits and physical characteristics required for the profession $(\mathrm{M}=4,6 ; \mathrm{SD}=0,89)$, the professions in demand that are available for the pupil with MID, advise on where they could acquire an appropriate profession (provide knowledge about acquisition of the profession ( $\mathrm{M}=4,6 ; \mathrm{SD}=0,55)$.

Vocational counselling. Perhaps the most important feature of prevocational education of pupils with MID is reconciliation of the pupil's wishes 
Aiste Valaikiene, Irena Kaffemaniene, Ingrida Baranauskiene. The Structure and Guidelines of Pre-Vocational Education and Assistance for Pupils with Mild Intellectual Disabilities

and his / her possibilities. According to experts, this is one of the key factors choosing the professional activity. It is necessary to find such activity for the pupil with MID which would be accessible for him / her and provide satisfaction. According to experts, already at the early stage of pre-vocational self-education the school must help the pupil with MID to understand his / her possibilities, realisticness of the choice $(\mathrm{M}=4,8 ; \mathrm{SD}=0,44)$ and provide assistance looking for the professional activity field in which he / she could participate (for each child to help to discover and acquire a profession, corresponding to his / her wishes and possibilities, $\mathrm{M}=4,8 ; \mathrm{SD}=0,44$; evaluation of abilities and possibilities of the pupil with MID, $\mathrm{M}=4,6 ; \mathrm{SD}=0,56)$. Thus, according to experts, choosing the profession, the pupil with MID has to know his / her physical characteristics, the health status; it is necessary to help the pupil to understand suitability of the profession on time. The opinions of the participants of Delphi survey are confirmed by Eisenman (2007). According to the author, the successful choice of the profession is based on the pupil's selfknowledge; it is necessary to help pupils to identify not only their professional interests but also their personality traits and abilities. Field, Martin, Miller, Ward \& Wehmeyer (1998) stated that understanding of their strengths and limitations together with faith in oneself as being able and efficient are essential components of self-determination and enable the person to better control his / her life and become a successful adult.

Preparation for the world of work. Pre-vocational education is not so much preparation for a particular profession but preparation for work in a broad sense (Laužackas 2005). As it was mentioned, people with MID both find it more difficult to adapt in the workplace and lack independent living skills (Baranauskienė \& Ruškus 2004; Hallahan \& Kauffman 2003, etc.). Therefore, experts relate preparation of pupils with MID for the world of work to the development of independent living skills $(\mathrm{M}=4,8 ; \mathrm{SD}=0,43)$, development of practical and social skills $(\mathrm{M}=4,8 ; \mathrm{SD}=0,44)$, creation of conditions to try out the profession practically $(\mathrm{M}=4,8 ; \mathrm{SD}=0,46)$.

Career planning. In the experts' opinion, the key objective of this prevocational education field should be assistance to the pupil purposely choosing the profession that would correspond to his / her abilities. Because persons with mild intellectual disabilities lack the ability to critically self-evaluate their abilities and possibilities, in the career planning stage the school should help the pupil to reconcile the image of the future work with self-evaluation of his / her their real possibilities (naming and adequate evaluation of one's wishes and possibilities $\mathrm{M}=4,8 ; \mathrm{SD}=0,45)$ and only then to plan one's actions seeking professional integration (planning the prospects of choosing life and profession, $\mathrm{M}=4,4 ; \mathrm{SD}=0,56$ ) and to choose the vocational education school (guidance to study in vocational schools, $\mathrm{M}=4,4 ; \mathrm{SD}=0,89)$. 
According to experts, the curriculum of pre-vocational education should consist of development of personality traits, social skills, general literacy and activity abilities and the lifelong learning approach. According to research participants, these are the most important factors of career education and professional integration. In the experts' opinion, pre-vocational education will be effective if it ensures holistic self-development of personality traits and value approaches. Experts accentuated development of the following personality traits, necessary for the professional career and independent life of pupils with MID: accuracy, diligence, responsibility, dutifulness, honesty ( $M=4,6$; $\mathrm{SD}=0,55) ;$ communicability $(\mathrm{M}=4,4 ; \mathrm{SD}=0,89) ;$ activeness, persistence, proactiveness, emotionality, sensitivity $(\mathrm{M}=4,2 ; \mathrm{SD}=0,44-0,83)$, etc. Experts also mentioned the importance of developing value approaches for professional integration, particularly the approach of quality work, respect for work (M=4,6; $\mathrm{SD}=0,54-0,55)$, etc. Statements of research participants about the importance of developing personality traits of pupils with mild intellectual disabilities are also confirmed by Heller \& Gitterman (2011); Leffert, Siperstein \& Millikan (2000) and other authors.

According to Delphi study participants, seeking professional integration of pupils with MID, it is particularly relevant to develop their social skills: communication, social participation, decision-making, self-control and emotional management skills.

According to experts, the priority aim of self-development of communication and social participation skills is creation of relations with other people and the society $(\mathrm{M}=4,6 ; \mathrm{SD}=0,55)$, therefore, according to experts, it is necessary to purposefully organize pupils' communication and collaboration with peers $(\mathrm{M}=4,6 ; \mathrm{SD}=0,56)$; help the pupil with MID to acquire social participation skills so that the person can feel full-fledged and necessary for the society $(\mathrm{M}=4,6, \mathrm{SD}=0,47)$, integrate in the society $(\mathrm{M}=4,6, \mathrm{SD}=0,55)$. It is relevant for these pupils' professional integration to provide assistance to another person and ask for assistance $(\mathrm{M}=4,6, \mathrm{SD}=0,89)$, work in a team $(\mathrm{M}=4,2, \mathrm{SD}=0,84)$.

Decision-making skills are a constituent of social cognition skills (Kaffemaniene \& Jurevičiene 2012). According to the authors, social cognition skills undoubtedly determine the quality of the person's social functioning. According to research participants, decision-making abilities $(\mathrm{M}=4,6, \mathrm{SD}=0,55)$, the ability to plan, predict consequences, formulate goals and achieve them, independently solve problems $(\mathrm{M}=4,4, \mathrm{SD}=0,85)$, etc. are important for professional integration of persons with mild intellectual disabilities. Experts' opinion is confirmed by Lefferts et al., (2000). According to the authors, persons with MID can be characterized by excessive conformity, obedience, strong dependence on other people; due to the lack of criticism they are at higher risk 
Aiste Valaikiene, Irena Kaffemaniene, Ingrida Baranauskiene. The Structure and Guidelines of Pre-Vocational Education and Assistance for Pupils with Mild Intellectual Disabilities

of becoming victims of manipulation. Therefore, at schools they have to be taught to recognize problems (related to work, interpersonal relations, etc.), respond to them appropriately and solve them. It should be noted that problemsolving skills are closely linked with the person's professional selfdetermination abilities. Field, Martin, Miller, Ward \& Wehmeyer (1998) described self-determination as a combination of knowledge, skills and beliefs directing the person to goal-oriented, self-regulated behaviour. Wehmeyer, Schwartz (1997; qtd. in Field et al., 1998) proved that persons with intellectual disabilities who had resolve skills were better assessed in employment situations and were able to achieve more than those without resolve skills.

Development of self-control, emotional management skills is a relevant and challenging part of preparation for integration of pupils with intellectual disabilities. Delfi group participants paid a lot of attention to the development of these skills. According to them, the aim of developing self-control and emotional management skills is development of emotions and will $(\mathrm{M}=4,6$; $\mathrm{SD}=0,53)$; and that requires the pupil's self-awareness abilities $(\mathrm{M}=4,6$; $\mathrm{SD}=0,54)$, abilities of behavioural and emotional control; perception of responsibility for one's behaviour $(\mathrm{M}=4,6 ; \mathrm{SD}=0,55)$, self-control $(\mathrm{M}=4,4$; $\mathrm{SD}=0,89)$, psychological resistance $(\mathrm{M}=4,2, \mathrm{SD}=0,83)$. Pupils must learn to resolve conflicts by means of appropriate behaviour $(\mathrm{M}=4,2 ; \mathrm{SD}=0,84)$.

Besides, experts emphasized relevance of general literacy and independent living abilities (teaching to calculate, write and communicate should be related to experience needed for life, $\mathrm{M}=4,6, \mathrm{SD}=0,55)$. Delfi group participants closely linked development of the lifelong learning approach to pupils' preparation for the modern world of work and career planning. Experts stated that more attention should be paid to learning motivation (to promote the wish to learn and continuously improve, $\mathrm{M}=4,8, \mathrm{SD}=0,45$ ) and development of abilities of flexibility with regard to novelties that are important in today's life (to be able to adapt to changing environmental conditions, $\mathrm{M}=4,6, \mathrm{SD}=0,55$ ). Development of lifelong learning approaches in the prevocational education process should help the pupil to understand that seeking better professional integration and personal life results, he / she will have to continuously learn and acquire new ways of work activities.

\section{Discussion}

Relevance of pre-vocational education for pupils with mild intellectual disabilities is grounded on these persons' particular educational needs and the analysis of their situation in the labour market. Scientific researches have demonstrated that children mild intellectual disabilities distinguish themselves by cognitive and personality peculiarities, which determine poorer academic 
performance at school and limit possibilities of choosing the profession. Therefore, pre-vocational self-education of pupils with MID necessitates individualized socio-educational assistance, based on the potential (strengths) of pupils with MID and taking into account peculiarities of their self-education: a slower learning pace, limited abilities of mastering information and practical application (Friend \& Bursuck 2012; etc.).

The multidisciplinary socio-educational assistance, grounded on individualised interaction, encompasses the very pupil's active self-education, teamwork of teachers and career counsellors, cooperation with the family and inter-institutional cooperation.

The choice of the profession corresponding to the areas of interest, possibilities and possessed abilities is a very important precondition for successful professional integration of pupils with MID. The best prevention of drop-out from the labour market is the right choice of the profession. The pupil with MID must be provided with individualized socio-educational assistance recognising one's strengths, self-evaluating one's possibilities and their coherence with work requirements and developing features needed for work.

According to Saleebey (1996) and other authors, the strengths perspective is successfully applied educating persons with various disabilities, including pupils with intellectual disabilities. The strengths perspective is closely related to promotion of the person's social participation and his / her empowerment, treating them as strategies in order to enhance individuals' social functioning possibilities. Pre-vocational education is seen as a precondition for active participation in the labour market.

From the pragmatism standpoint, self-development of social skills, prosocial behaviour and life skills in the pre-vocational stage are the most important curriculum guidelines preparing pupils with MID for independent life. Their education is possible through practical type activities and tasks, focusing on special educational needs so that they can give the greatest benefit for the pupil's preparation for professional integration. The idea of pre-vocational education would be unjustified without a deeper analysis of its links with the labour market requirements and these pupils' professional integration opportunities. There should be a particular focus on the formation of these pupils' value system, enhancement of positive attitude to work and motivation of self-education for the profession, assistance realising one's life prospects and goals.

Changes in pre-vocational education are necessary both at school and beyond it. Readiness of schools to educate pupils with MID encompasses both improvement of pre-vocational curricula, process and the increase of activeness of the pupil, his / her family, assurance of inter-institutional cooperation and continuity of the socio-educational assistance for the person. 
Aiste Valaikiene, Irena Kaffemaniene, Ingrida Baranauskiene. The Structure and Guidelines of

Pre-Vocational Education and Assistance for Pupils with Mild Intellectual Disabilities

\section{Conclusions}

1. Pre-vocational education of pupils with MID must be based on a holistic concept: long-term multi-disciplinary socio-educational assistance strategies, oriented to the person's individuality, and the system of complex pre-vocational education objectives.

2. The key pre-vocational education strategies of pupils with mild intellectual disabilities are: 1) the strengths perspective; 2) the individualized multidisciplinary socio-educational assistance based on the interaction of the pupil, his / her parents, teachers, career guidance specialists.

3. In the stage of pre-vocational education, the pupil must receive assistance recognizing his / her strengths and limitations of possibilities, solving problems related to coping with personal professional integration barriers. Pre-vocational education must correspond to pupils' special educational needs and help to achieve quality of professional and personal life.

4. Pre-vocational education of pupils with MID must focus on the learner's experience, be based on the pupil's experience and develop experience at the level accessible to him / her. Practicality and usefulness in life are essential pre-vocational education principles of pupils with mild intellectual disabilities.

\section{References}

Baer, R. M., Daviso, A. W., Flexer, R. W., Queen, R. M., \& Meindl, R. S. (2011). Students with Intellectual Disabilities: Predictors of Transition Outcomes. Career Development for Exceptional Individuals, 34 (3), 132-141. DOI: 10.1177/0885728811399090.

Baranauskienè, I., Radzevičienè, L., \& Valaikienè, A. (2012). Introduction. In: Baranauskienè, I., Kossewska, J. (Eds.). Vocational Counselling for children \& Youth with Special Educational Needs: Parameters of the Ideal Model. Scientific Study (pp. 9-16). Kraków: Wydawnictwo Naukowe Uniwersytetu Pedagogicznego.

Baranauskienè, I., \& Ruškus, J. (2004). Neigaliuju dalyvavimas darbo rinkoje: profesinio rengimo ir profesines adaptacijos sqveika. Monografija. Šiauliai: Šiaulių universiteto leidykla.

Colella, A. (1996). Organizational Socialization of Newcomers with Disabilities: Framework for Future Research. Research in Personnel and Human Resources Management, 14, 351-417. EBSCO Publishing.

Eisenman, L. T. (2007). Self-Determination Interventions: Building a Foundation for School Completion. Remedial and Special Education, 28 (1), 2-8. DOI: 10.1177/07419325070280010101.

Field, S., Martin, J., Miller, R., Ward, M., \& Wehmeyer, M. (1998). Self-determination for persons with disabilities: A position statement of the division on career development and transition. Career Development for Exceptional Individuals, 21 (2), 113-128. DOI: $10.1177 / 088572889802100202$. 
Friend, M., \& Bursuck, W. D. (2012). Including Students with Special Needs: a Practical Guide for Classroom Teachers. USA: Pearson.

Hallahan, P. D., \& Kauffman, J. M. (2003). Exceptional Children. Introduction to Special Education $\left(9^{\text {th }}\right.$ ed.). Boston: Allyn \& Bacon.

Heller, N. R., \& Gitterman, A. (2011). Mental Health and Social Problems: A Social Work Perspective. USA: Routledge. ISBN\#978-0-415-49387-1.

Hsu, Ch., \& Sandford, B. A. (2007). The Delphi Technique: Making Sense of Nonsensus. Practical Assessment. Research \& Evaluation, 12 (10). Retrieved June 15, 2014, from http://pareonline.net/getvn.asp? $\mathrm{v}=12 \& \mathrm{n}=10$

Kaffemanienè, I., \& Jurevičienè, M. (2012). Opportunities for Modelling Social Skills Education Based on the Individual's Strengths. Special Education, 2 (27), 175-186. Downloaded from http://www.sumc.su.lt/images/journal2012_2_27/25_kaffemaniene_ jureviciene_en_doc.pdf

King, A. S. (1993). Doing the Right Thing for Employees with Disabilities. Training \& Development, 47 (9), 44-47. ISSN-1055-9760. Downloaded from EBSCO Publishing.

Kuijpers, M., Meijers, F., \& Gundy, C. (2011). The Relationship Between Learning Environment and Career Competencies of Students in Vocational Education. Journal of Vocational Behavior, 78 (1), 21-30. ISSN: 0001-8791. DOI:10.1016/j.jvb.2010.05.005.

Laužackas, R. (2005). Profesinio rengimo terminu aiškinamasis žodynas $=$ Terminology of Vocational Education and Training. Kaunas" Vytauto Didžiojo universiteto leidykla.

Leffert, J. S., Siperstein, G. N., \& Millikan, E. (2000). Understanding Social Adaptation in Children with Mental Retardation: A Social Cognitive Perspective. Exceptional Children, 66, 530-545.

Linstone, H. A., \& Turoff, M. (2002). The Delphi Method Techniques and Applications. USA. Downloaded from http://is.njit.edu/pubs/delphibook/

Rivera, L. M., \& Pellitteri, J. S. (2007). Attending to the Career Development Needs of Middle School Students with Learning Disabilities. Insights on Learning Disabilities, 4 (2), 49-64. Downloaded from EBSCO host.

Sackman, H. (1974). Delphi Assessment: Expert Opinion, Forecasting, and Group Process. Santa Monica, Calif.: RAND Corporation, R-1283-PR, 1974. Downloaded from http://www.rand.org/pubs/reports/R1283.html

Saleebey, D. (1996). The Strengths Perspective in Social Work Practice: Extensions and Cautions. Social Work, 41 (3), 296-305.

Ugdymo karjerai programa (2014). Teisès aktų registras, 2014-04-29, Nr. 2014-04888.

Wagner, M., \& Davis, M. (2006). How are We Preparing Students With Emotional Disturbances for the Transition to Young Adulthood? Journal of Emotional and Behavioral Disorders, 14 (2), 86-98. 